\title{
PEMBERDAYAAN REMAJA DESA WUKIRSARI DI KABUPATEN BANTUL SEBAGAI AGENT OF CHANGE MELALUI PROMOSI KESEHATAN MINUMAN LOKAL WEDANG UWUH
}

\author{
Khoiriyah Isni $^{1 *}$, Septian Emma Dwi Jatmika1, Kintoko² \\ ${ }^{1}$ Fakultas Kesehatan Masyarakat, Universitas Ahmad Dahlan, Yogyakarta, Indonesia \\ ${ }^{2}$ Fakultas Farmasi, Universitas Ahmad Dahlan, Yogyakarta, Indonesia \\ *Penulis Korespondensi : khoiriyah.isni@ikm.uad.ac.id
}

\begin{abstract}
Abstrak
Desa Wukirsari di Kabupaten Bantul merupakan daerah penghasil wedang uwuh. Wedang uwuh dikenal sebagai minuman lokal yang berkhasiat untuk kesehatan. Hampir seluruh masyarakat di Desa Wukirsari berprofesi sebagai pengrajin wedang uwuh. Namun demikian, potensi ini kurang disadari oleh masyarakat, sehingga nilai jual masih sangat rendah. Guna meningkatkan nilai jual, diperlukan suatu inovasi dengan memanfaatkan salah satu potensi yang ada yaitu remaja sebagai agent of change dan promotor kesehatan. Remaja dengan keterampilan hidup yang tinggi, misalnya keterampilan presentasi dan konseling sebaya dapat menjadi solusi terhadap peningkatan nilai jual produk wedang uwuh. Metode yang digunakan dalam pemberdayaan ini yaitu pendidikan masyarakat atau penyuluhan, pelatihan atau praktik, dan simulasi. Tujuannya adalah remaja memiliki pengetahuan dan keterampilanyang memadai. Output kegiatan ini yaitu remaja memiliki pengetahuan dan keterampilan terkait presentasi dan konseling sebaya, serta diseminasi kegiatan berupa produk publikasi dan modul pelatihan. Secara umum, kegiatan pemberdayaan ini diterima oleh remaja, efektif meningkatkan pengetahuan dan keterampilan remaja sebagai agent of change promotor kesehatan berupa teknik presentasi dan konseling sebaya, evaluasi proses menunjukkan hasil yang bagus terhadap kegiatan pemberdayaan ini. Harapannya kegiatan ini dapat dilanjutkan pada tingkat forum organisasi karang taruna, sehingga keterampilan hidup dimiliki oleh seluruh remaja di Desa Wukirsari Kabupaten Bantul.
\end{abstract}

Kata kunci : Wedang Uwuh, Promotor Kesehatan, Wukirsari, Bantul

\begin{abstract}
Wukirsari Village in Bantul Regency is a producer of wedang uwuh. Wedang uwuh known as a local beverage that is beneficial for health. Almost all people in Wukirsari village work as wedang uwuh craftsmen. However, this potential is less realized by the community, so the selling price is still very low. In order to increase the selling value, an innovation is needed by utilizing one of the existing potential of adolescents as agent of change and health promoter. Adolescents with high life skills, such as presentation skills and peer counseling can be a solution to increasing the value of selling products wedang uwuh. The methods was used in this empowerment are community education or counseling, training or practice, and simulation. The goal is that adolescents have adequate knowledge and skills. The output of this activity is teenagers have knowledge and skills related to peer presentation and counseling, and dissemination activities in the form of publication products and training modules. In general, these empowerment activities are accepted by adolescents, effectively increasing the knowledge and skills of adolescents as agents of change health promoters in the form of peer presentation and counseling techniques, process evaluation shows good results on these empowerment activities. Hopefully this activity can be continued at the forum level of youth organization, so that life skills are owned by all teenagers in Wukirsari Village, Bantul Regency.
\end{abstract}

Keywords : Wedang Uwuh, Health Promotor, Wukirsari, Bantul

\section{PENDAHULUAN}

Masa remaja merupakan periode tahap pertumbuhan dan perkembangan yang sangat pesat baik secara fisik, psikologis, maupun intelektual. Sifat paling khas dari remaja yakni memiliki rasa ingin tahu yang sangat besar, menyukai petualangan dan tantangan serta terkadang cenderung berani menanggung risiko atas perbuatannya tanpa didahului oleh pertimbangan dan pemikiran yang matang. Apabila keputusan yang diambil secara spontan tersebut tidak tepat, maka 
mereka akan jatuh ke dalam perilaku berisiko dan akibat yang ditanggung dapat berupa jangka pendek dan jangka panjang dalam berbagai masalah kesehatan fisik dan psikosial. Hal inilah yang menjadi pemicu banyaknya kasus terkait dengan perilaku remaja yang tidak aman.

Jumlah kelompok remaja usia 10-24 tahun di Indonesia menurut Sensus Penduduk 2010 sebanyak 64 juta jiwa atau sekitar 27,6\% dari total penduduk yaitu 237,6 juta jiwa. Sedangkan di Daerah Istimewa Yogyakarta tercatat jumlah penduduk usia 10-24 tahun sekitar 834.922 jiwa atau 35\% dari total penduduk Daerah Istimewa Yogyakarta yang berjumlah 2.950.721. Data menujukkan bahwa jumlah remaja laki-laki di Daerah Istimewa Yogyakarta lebih banyak daripada jumlah remaja perempuan. Jumlah remaja laki-laki adalah 425.807 jiwa, sedangkan remaja perempuan 409.115 jiwa (Badan Pusat Statistik, 2010).

Dewasa ini, remaja dan permasalahannya yang menjadi sorotan berkaitan dengan kesehatan reproduksi dan seksualitas, seperti perilaku seksual yang berisiko, merokok, penyalahgunaan obat dan kekerasan fisik berhubungan dengan kehamilan pertama pada remaja (Cavazos-Rehg et al., 2010). Center for Disease Control and Prevention (CDC) menyatakan bahwa penduduk remaja usia 10 sampai dengan 19 tahun di seluruh dunia telah melakukan hubungan seksual aktif (CDC, 2002). Menurut Pusat Studi Seksualitas Perkumpulan Keluarga Berencana Indonesia (PKBI) Yogyakarta menyatakan telah terjadi perubahan pandangan remaja terhadap perilaku seks sebelum menikah. Remaja di Daerah Istimewa Yogyakarta yang pacaran sebanyak $12.1 \%$ pernah berhubungan seksual (PKBI DIY, 2017). Hal tersebut juga tercermin dari jumlah pasangan yang mengajukan permohonan dispensasi kawin di Bantul yang meningkat dari 70 pasangan pada tahun 2008 menjadi 115 pada bulan oktober tahun 2011 (Kurniawan, 2011).

Melihat fenomena tersebut, diperlukan suatu pemberdayaan sehubungan dengan pendidikan keterampilan hidup (life skill education) bagi para remaja, sehingga remaja dapat menghindari hal-hal yang tidak diinginkan, dan merugikan masa depan. Permasalahan remaja ini ditangkap sebagai peluang emas bagi tim Kuliah Kerja Nyata (KKN) Pembelajaran Pemberdayaan Masyarakat (PPM) dari Universitas Ahmad Dahlan (UAD) di Kelurahan Wukirsari, Imogiri, Bantul. Tim KKN PPM UAD di Kelurahan Wukirsari, Imogiri, Bantul berusaha untuk menjembatani antara remaja dan potensi wilayah tersebut. Sehingga potensi wilayah juga diketahui oleh remaja dan remaja dapat berperan serta dalam meningkatkan potensi wilayahnya dengan keterampilan hidup yang dimiliki. Adapun potensi wilayah kelurahan Wukirsari yang dapat menjadi lahan remaja untuk meningkatkan keterampilan hidup adalah wedang uwuh.
Wedang uwuh, wedang khas dari Imogiri, yang terkenal dengan makam raja-raja. Menurut masyarakat sekitar, wedang ini dulunya menjadi sajian khas para raja untuk menjamu tamunya. Oleh karena itu wedang uwuh sampai saat ini masih banyak dilestarikan. Wedang uwuh bukanlah wedang yang bisa dengan mudah didapatkan di sembarang tempat. Jika menginginkan wedang ini harus rela berkunjung ke Imogiri atau pasar-pasar tradisional di sekitarnya. Melihat perkembangan Imogiri sekarang ini yang terus berkembang menjadi daerah wisata, keberadaan wedang uwuh menjadi satu daya tarik tersendiri bagi wisatawan, selain menikmati indahnya pesona alam Pajimatan Imogiri (Munawaroh, 2014). Hal inilah yang harus diketahui para remaja Kelurahan Wukirsari, baik dari segi sejarah, komposisi herbal, manfaat masing-masing komposisi herbal, dan cara pemasaran wedang uwuh. Oleh karena itu, diperlukan suatu pemberdayaan keterampilan hidup kepada remaja sehingga remaja dapat menjadi promotor kesehatan wedang uwuh dan dapat berkontribusi dalam mengangkat suatu produk kearifan lokal (local wisdom) tidak hanya pada tingkat Kecamatan Imogiri saja, tetapi juga ke tingkat internasional.

Kegiatan ini tergolong kegiatan yang baru bagi masyarakat Imogiri, khususnya pengrajin wedang uwuh. Kegiatan sebelumnya adalah memberikan pelatihan dan penyuluhan kepada ibu-ibu PKK dan penjual wedang uwuh di Dukuh Pajimatan sehubungan dengan pengawetan dan penyajian wedang uwuh dalam bentuk instan dan celup (Kristianingrum et al., 2009). Sementara itu, kegiatan lain yang serupa dengan sasarannya adalah ibu-ibu PKK di wilayah RT 58 dan RT 59 RW 14 Kelurahan Mojorejo, Kecamatan Taman, Kota Madiun. Kegiatan yang dilakukan berupa pelatihan pembuatan ramuan herbal wedang uwuh. Ramuan herbal wedang uwuh terdiri dari kayu secang, kayu manis, jahe, serai, gula aren, dan susu (Sumani, Wuryantoro, \& Kuswardani, 2016). Kegiatan lainnya sehubungan dengan wedang uwuh berupa transfer of knowledge berupa pemberian formula wedang uwuh dan teh celup. Bahan berasal dari tanaman yang dibudidayakan oleh masyarakat Dusun Purut, Desa Parang Kecamatan Banyakan, Kabupaten Kediri (Purwitasari, Prajogo, \& Studiawan, 2016).

Kajian-kajian ilmiah telah banyak dilakukan guna menambah nilai dan dampak kesehatan dari wedang uwuh. Namun demikian, hal tersebut tidak dapat mencapai hasil yang maksimal apabila tidak dilakukan promosi kesehatan, dan dilakukan oleh generasi muda. Berdasarkan beberapa kegiatan serupa yang telah dilakukan sebelumnya, maka ditemukan suatu kebaharuan pada kegiatan pemberdayaan ini. Kebaharuan kegiatan dibuktikan dari tema, metode, dan sasaran kegiatan pemberdayaan. Kegiatan pemberdayaan ini tidak hanya memunculkan kebaharuan IPTEKS, namun juga bersifat orisinil secara ilmiah. Kegiatan pemberdayaan ini bertujuan 
sebagai upaya meningkatkan dan menginisiasi keterampilan hidup yang wajib dimiliki oleh seorang remaja. Sehingga remaja dapat menjadi agen perubahan (agent of change) dan menjadi promotor kesehatan dalam memperkenalkan serta mempromosikan wedang uwuh sebagai minuman kesehatan khas Desa Wukirsari di Kabupaten Bantul, Daerah Istimewa Yogyakarta.

\section{BAHAN DAN METODE}

Kegiatan Pemberdayaan Remaja Kelurahan Wukirsari sebagai promotor Kesehatan wedang uwuh dilaksanakan oleh Tim Pengusung KKN PPM UAD yang terdiri dari tiga orang dosen UAD, dari Fakultas Kesehatan Masyarakat dan Fakultas Farmasi. Pelaksanaan kegiatan pemberdayaan ini bekerja sama dengan mahasiswa KKN PPM UAD periode 63 Divisi II.A tahun 2017. Sasaran program ini adalah remaja di Kelurahan Wukirsari, Imogiri, terutama dusun Karang kulon, Kedung buweng, dan Pundung.

Bahan utama yang digunakan dalam kegiatan pemberdayaan kepada remaja ini adalah pendidikan keterampilan hidup remaja berupa teknik presentasi dan teknik konseling sebaya. Materi terkait pendidikan keterampilan hidup remaja terdapat dalam buku yang diterbitkan oleh Badan Koordinasi dan Keluarga Berencana Nasional (BKKBN) tahun 2008 yang berjudul "Kurikulum dan Modul Pelatihan Pengelolaan Pusat Informasi dan Konseling Kesehatan Reproduksi Remaja (PIK-KRR)" dan buku tentang "Pendidikan Kecakapan Hidup untuk Pencegahan HIV dan AIDS" yang diterbitkan oleh Pusat Pengembangan Kualitas Jasmani Departemen Pendidikan Nasional tahun 2007. Disamping itu, bahan utama kegiatan ini juga merujuk pada buku yang berjudul "Modul Pelatihan Kesehatan Reproduksi Bagi Calon Konselor Sebaya" terbitan BKKBN tahun 2008.

Metode yang digunakan dalam pelaksanaan kegiatan pemberdayaan ini adalah sebagai berikut :

a) Pendidikan masyarakat atau penyuluhan, sebagai upaya mengawali proses pemberdayaan dan pelatihan, bertujuan untuk menghasilkan perubahan sudut pandang peserta terhadap keterampilan dan peran remaja dan manfaat wedang uwuh sebagai minuman kesehatan, serta peran remaja dalam memperkenalkan wedang uwuh. Materi pendidikan masyarakat atau penyuluhan bermuatan utama terkait definisi remaja, peran remaja, keterampilan yang harus dimiliki oleh remaja, dan wedang uwuh sebagai minuman kesehatan termasuk komposisi, manfaat masing-masing komposisi dan manfaat tambahan formulasi baru serta cara pemasarannya.

b) Pelatihan atau praktik, sebagai upaya lanjutan dalam proses pemberdayaan, yang bertujuan untuk meningkatkan kecakapan atau keterampilan remaja sebagai promotor kesehatan wedang uwuh minuman kesehatan. c) Simulasi, sebagai upaya akhir mensinergikan antara pengetahuan mengenai keterampilan hidup remaja dan potensi kearifan lokal (local wisdom) wedang uwuh yang diperoleh melalui proses pendidikan masyarakat atau penyuluhan dengan pelatihan atau praktik. Sehingga hasil yang diperoleh lebih maksimal dengan adanya simulasi. Simulasi yang dilakukan meliputi simulasi presentasi sebagai narasumber dan simulasi konseling sebaya berdasarkan studi kasus yang diberikan oleh fasilitator.

Pengumpulan data dilakukan melalui teknik observasi dan dokumentasi kegiatan. Selanjutnya, analisisa data dilakukan dengan pendekatan kuantitatif dan kualitatif, yaitu dengan mendeskripsikan skor rata-rata dari evaluasi proses kegiatan, lembar evaluasi keterampilan presentasi, dan keterampilan konseling sebaya.

Kegiatan pemberdayaan ini dilakukan selama 300 menit atau 5 jam yaitu pada hari Senin, tanggal 28 Agustus 2017, mulai pukul 14.00 - 19.00 WIB. Bertempat di ruang Aula pertemuan Desa Wukirsari, Imogiri, Bantul, DIY yang dihadiri oleh 22 peserta dengan rentang usia 17-21 tahun.

\section{HASIL DAN PEMBAHASAN \\ 3.1 Hasil}

\section{1) Pendidikan Kesehatan atau Penyuluhan}

Kegiatan pemberdayaan kepada remaja diawali dengan sesi pertama yaitu transfer pengetahuan atau pemberian pendidikan kesehatan kepada para peserta. Pemberian teori ini dimaksudkan untuk menunjang pengetahuan dan wawasan peseta terkait konsep diri remaja dan potensi kearifan lokal yang berada di sekitar remaja Desa Wukirsari, Imogiri, Bantul, DIY. Materi pendidikan kesehatan diberikan oleh salah satu Tim pengusung KKN PPM yaitu Khoiriyah Isni. Adapun materi yang diberikan meliputi definisi remaja, peran serta remaja, permasalahan remaja, dan keterampilan hidup remaja. Kemudian, peserta diberikan materi terkait teknik presentasi dan teknik konseling sebaya (Gambar 1).

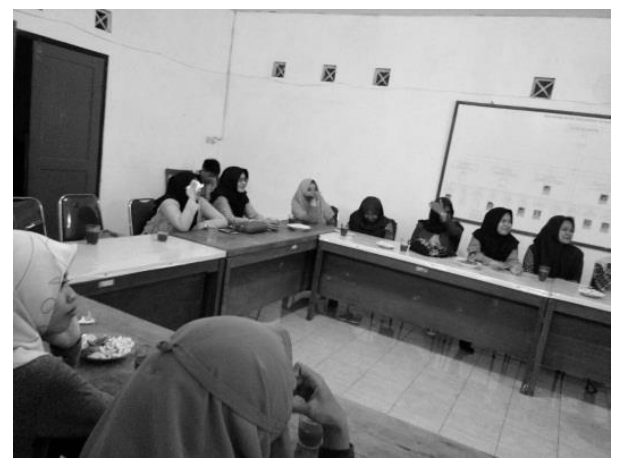

Gambar 1. Peserta sedang memperhatikan materi pendidikan kesehatan atau penyuluhan terkait remaja 
Selanjutnya, peserta diberikan pengetahuan terkait kearifan lokal (local wisdom) yang berada di sekitar peserta, termasuk produk wedang uwuh. Pengetahuan terkait wedang uwuh meliputi komponen herbal wedang uwuh, khasiat kesehatan dari masing-masing komponen wedang uwuh, formulasi wedang uwuh, dan bentuk sediaan wedang uwuh, yang disampaikan oleh Kintoko.

\section{2) Pelatihan atau Praktik}

Tahap selanjutnya setelah diberikan pengetahuan terkait peran remaja, teknik presentasi, dan teknik konseling sebaya serta pengetahuan tentang produk wedang uwuh dari segi kesehatan, peserta dibagi menjadi 2 (dua) kelompok dan masing-masing kelompok diberikan kasus yang berbeda-beda. Masing-masing kelompok diberikan tugas untuk menganalisis, mendiskusikan, dan memberikan alternative solusi dari maslaah yang yang ada di dalam kasus, dipandang dari sisi remaja (Gambar 2).

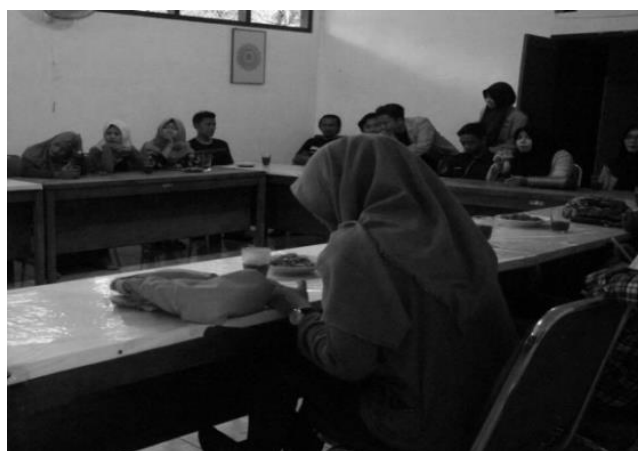

Gambar 2. Peserta sedang membaca dan berdiskusi terkait studi kasus yang diberikan fasilitator

Pemberian studi kasus ini bertujuan agar peserta mampu menyadari masalah dan potensi yang ada disekitarnya. Disamping itu juga agar peserta yang masih remaja ini mampu memahami, menganalisis situasi, dan memberikan solusi penyelesaian masalah serta mempraktikkan keterampilan hidup sesuai dengan situasi dan kondisi yang sedang dihadapi, baik diri sendiri maupun sesama remaja lain. Pemecahan masalah meliputi keterampilan yang akan didemonstrasikan remaja yaitu presentasi atau konseling remaja. Masing-masing peserta akan diberikan lembar penilaian keterampilan presentasi dan konseling sebaya. Lembar penilaian ini memuat keterampilan yang seharusnya ditunjukkan ketika melakukan presentasi atau konseling. Tujuannya adalah peserta dapat mengevaluasi keterampilan presentasi dan konseling sebaya yang sedang didemonstrasikan oleh kelompok lain.

\section{3) Simulasi}

Metode ketiga yang digunakan dalam pelaksanaan kegiatan pemberdayaan ini adalah simulasi. Simulasi dimaksudkan untuk mensinergikan antara pengetahuan dari pendidikan kesehatan yang telah diberikan dan keterampilan yang telah dipraktikkan.
Bahan simulasi berasal dari hasil studi kasus masingmasing kelompok. Masing-maisng kelompok menunjuk satu perwakilan dari kelompoknya untuk mensimulasikan keterampilan hidup yang diplih sebagai alternative solusi penyelesaian masalah atas studi kasus yang diberikan fasilitator. Kelompok lain menilai simulasi yang dilakukan oleh kelompok lainnya (Gambar 3).

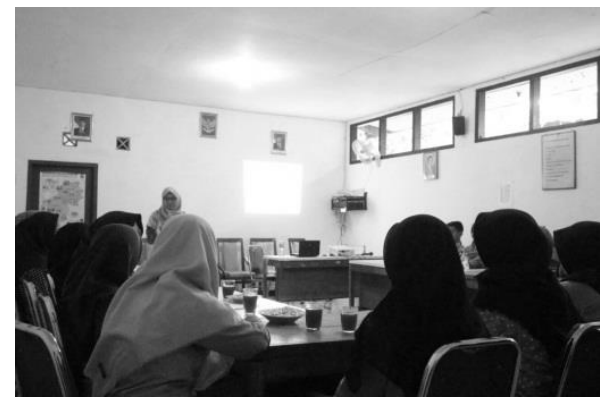

Gambar 3. Salah satu perwakilan kelompok sedang melakukan simulasi teknik presentasi

Penilaian simulasi sesuai dengan lembar evaluasi yang telah diberikan oleh fasilitator. Harapannya, baik peserta yang tidak mendemonstrasikan dan peserta yang mendemonstrasikan keterampilan presentasi dan konseling sebaya, dapat mengetahui dan mengevaluasi dengan benar teknik-teknik presentasi dan konseling sebaya.

\section{4) Evaluasi Proses}

Evaluasi kegiatan dilakukan dengan memberikan angket berupa lembar penilaian terhadap proses kegiatan pemberdayaan yang dilakukan, sehingga evaluasi berfokus pada proses bukan hasil dari kegiatan pemberdayaan. Adapun hasil evaluasi proses kegiatan pemberdayaan, disajikan dalam tabel berikut: 
Tabel 1. Evaluasi Proses Kegiatan Pemberdayaan Remaja sebagai Agent of Change melalui Promotor Kesehatan Minuman Lokal Wedang Uwuh di Desa Wukirsari Kabupaten Bantul, DIY

\begin{tabular}{lccccc}
\hline \multicolumn{1}{c}{ Kategori Penilaian } & $\begin{array}{c}\text { Buruk } \\
(\boldsymbol{\%})\end{array}$ & $\begin{array}{c}\text { Kurang } \\
(\boldsymbol{\%})\end{array}$ & $\begin{array}{c}\text { Cukup } \\
(\boldsymbol{\%})\end{array}$ & $\begin{array}{c}\text { Bagus } \\
(\boldsymbol{\%})\end{array}$ & $\begin{array}{c}\text { Memuaskan } \\
(\boldsymbol{\%})\end{array}$ \\
\hline Pelaksanaan Pelatihan & & & & & \\
Tema Pelatihan & 0 & 0 & 15 & 77 & 8 \\
Kelengkapan Materi & 0 & 8 & 23 & 46 & 23 \\
Sikap Penyelenggaraan & 0 & 0 & 8 & 54 & 38 \\
Alat Bantu & 0 & 8 & 15 & 62 & 15 \\
\hline Narasumber & 0 & 0 & 8 & & \\
Penguasaan Masalah & 0 & 0 & 15 & 62 & 31 \\
Cara penyajian & 0 & 0 & 8 & 54 & 38 \\
Manfaat materi & 0 & 0 & 15 & 23 & 62 \\
Interaksi dengan peserta & 0 & 8 & 8 & 62 & 23 \\
Penggunaan alat bantu & & & & & \\
\hline Lain-lain & 8 & 15 & 15 & 46 & 15 \\
Makanan & 8 & 23 & 31 & 31 & 15 \\
Sound system & 0 & 0 & 38 & 46 & \\
Gedung/ruangan & & & & & \\
\hline Sumber: Data Primer, 2017 & & & & & \\
\hline
\end{tabular}

Sumber : Data Primer, 2017

\subsection{Pembahasan}

Kegiatan pemberdayaan masyarakat ini diikuti oleh remaja putra dan putri dari Desa Wukirsari di Kabupaten Bantul. Terdapat 3 (tiga) dusun yang menjadi fokus kegiatan pemberdayaan ini yaitu Dusun Karang Kulon, Dusun Kedung Buweng, dan Dusun Pundung. Tiga dusun ini merupakan lokasi KKN PPM yang mengangkat potensi kearifan lokal (local wisdom) wedang uwuh, yang mana tiga dusun ini adalah dusun-dusun dengan jumlah pengrajin wedang uwuh terbanyak dibandingkan dengan dusun-dusun lain di Desa Wukirsari, Imogiri, Bantul.

Kegiatan pemberdayaan dibuka dengan perkenalan dan ice breaking. Perkenalan beruntun, sehingga semua peserta harus mengetahui nama-nama peserta yang hadir. Ice breaking diawal kegiatan bertujuan agar suasana menjadi lebih santai dan tidak tegang dengan mengenal peserta satu sama lain.

Secara umum, pelaksanaan kegiatan pemberdayaan ini dibagi menjadi 3 (tiga) yaitu transfer pengetahuan melalui pendidikan kesehatan atau penyuluhan, pelatihan atau praktik, dan simulasi. Ketiga formulasi metode ini diharapkan dapat menunjang peningkatan keterampilan hidup remaja sebagai agent of change melalui promosi kesehatan minuman lokal wedang uwuh. Peningkatan keterampilan hidup remaja diantaranya dapat dilihat dari keterampilan presentasi dan keterampilan konseling sebaya. Konsep kegiatan pemberdayaan ini dapat dilihat pada gambar 4, sebagai berikut :

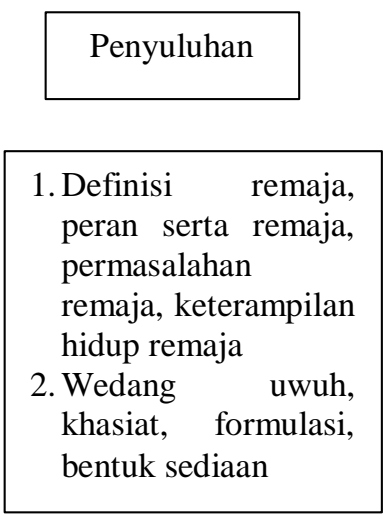

\begin{tabular}{|l|}
\hline 1. Keterampilan \\
presentasi \\
2. Keterampilan \\
konseling sebaya \\
\hline
\end{tabular}

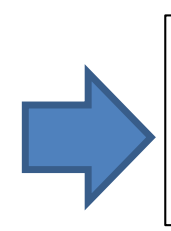
1. Studi kasus
2. Teknik
Presentasi dan konseling sebaya

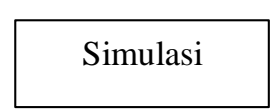

Praktik

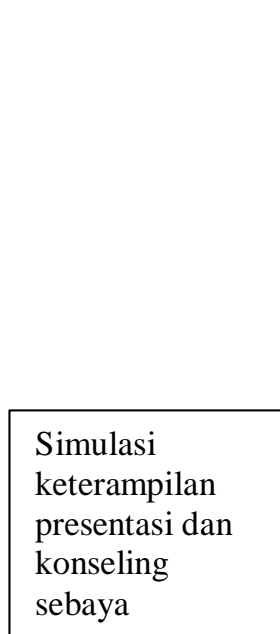

Gambar 4. Konsep Kegiatan Pemberdayaan Remaja Desa Wukirsari di Kabupaten Bantul sebagai Agent of Change melalui Promosi Kesehatan Minuman Lokal Wedang uwuh 
Pemberian keterampilan presentasi dan konseling sebaya dirasa sesuai dengan kebutuhan remaja dewasa ini. Keterampilan presentasi memberikan pengalaman berupa pengetahuan dan praktik kepada remaja sebagai seorang narasumber atau public speaker. Hal ini dilakukan sebagai wujud dari sikap dan naluri seorang remaja yang cenderung ingin tampil sehingga mendapatkan pengakuan dari lingkungan sekitar, atau sebagai wujud dari eksistensi diri. Sedangkan konseling sebaya merupakan keterampilan yang sesuai dengan remaja karena remaja cenderung bercerita dan meminta saran serta mendapatkan informasi dari teman sebaya. Penelitian menunjukkan bahwa sumber utama informasi kesehatan remaja adalah teman sebaya $(64,4 \%)$, yang mana informasi tersebut tidak dapat dipertangungjawabkan kebenarannya (Rahman et al., 2011). Penelitian lainnya menyebutkan bahwa sumber informasi kesehatan remaja di suatu sekolah, berasal dari teman atau media massa (Oljira, Berhane, \& Worku, 2013).

Remaja sebagai promotor kesehatan wedang uwuh, haruslah memiliki pengetahuan yang luas terkait kesehatan remaja secara umum dan wedang uwuh secara khusus. Jenis keterampilan yang diberikan dalam kegiatan pemberdayaan ini harapannya mampu meningkatkan pengetahuan, sikap dan perilaku remaja dalam bidang kesehatan. Penelitian membuktikan bahwa terdapat pengaruh antara pemberian penyuluhan terhadap pengetahuan pada remaja awal terkait narkoba. Adanya pengaruh ini ditunjukkan dengan peningkatan jumlah responden yang berpengetahuan baik setelah diberikan penyuluhan terkait Napza (Wiyani, Yudiernawati, \& Maemunah, 2017).

Harapannya dengan pemberian keterampilan presentasi dan konseling sebaya, para remaja di Kelurahan Wukirsari dapat mengaplikasikan dikehidupan nyata terutama dalam mengenalkan dan mempromosikan potensi lokal yaitu wedang uwuh sebagai minuman kesehatan khas Imogiri. Sementara itu, evaluasi proses dimaksudkan untuk menilai keberhasilan penyelenggaraan suatu kegiatan yang dinilai dari segi narasumber atau fasilitator, konsep pelatihan, dan sarana prasarana. Berdasarkan tabel 1, dapat dilihat bahwa sebanyak $77 \%$ peserta menilai tema pelatihan termasuk kategori bagus, karena sesuai dengan usia remaja, sebanyak $46 \%$ peserta menilai bagus untuk kelengkapan materi pelatihan. Sebanyak $54 \%$ peserta menilai bagus untuk sikap penyelenggara pelatihan dan sebesar $62 \%$ peserta menilai bagus utuk pengggunaan alat bantu pelatihan. Apabila dinilai dari segi pemberi materi atau narasumber, sebanyak $62 \%$ peserta menilai bagus untuk penguasaan masalah, cara penyajian, dan penggunaan alat bantu pelatihan serta interaksi dengan peserta. Kemudian, sebesar 54\% menilai bagus untuk manfaat materi pelatihan yang disampaikan.
Evaluasi proses kegiatan pelatihan juga mencakup sarana dan prasarana, seperti makanan, sound system, dan gedung/ruangan. Sebesar $46 \%$ peserta menilai bagus dari segi makanan dan ketersediaan gedung/ruangan, dan sebesar $31 \%$ peserta menyatakan bagus untuk ketersediaan sound system. Harapannya hasil evaluasi proses ini dapat digunakan sebagai bahan pertimbangan dan acuan ketika peserta akan mengadakan kegiatan yang serupa dalam kegiatan karang taruna. Sehingga pelaksanaan dapat berjalan maksimal dan meminimalisir kendala yang dapat terjadi.

\section{KESIMPULAN}

Berdasarkan kegiatan yang telah dilakukan, dapat disimpulkan bahwa kegiatan pemberdayaan remaja Desa Wukirsari di Kabupaten Bantul sebagai agent of Change melalui promosi kesehatan minuman lokal wedang uwuh dalam bentuk pendidikan kesehatan atau penyuluhan, praktik, dan simulasi berjalan sesuai dengan rencana dan menunjukkan hasil sesuai dengan tujuan. Hasil evaluasi proses menunjukkan pelaksanaan kegiatan dinilai bagus, dengan kriteria penilaiaan tema pelatihan (77\%), kelengkapan materi (46\%), sikap penyelenggara (54\%), dan penggunaan alat bantu $(62 \%)$.

Implikasi kegiatan pemberdayaan ini dalam pengembangan kehidupan remaja Desa Wukirsari adalah dapat diimplementasikan dikehidupan seharihari dan dapat diteruskan kepada remaja lainnya yang belum mengikuti kegiatan serupa dalam forum organisasi remaja yaitu karang taruna. Tentunya hal ini membutuhkan dukungan dari stakeholder setempat.

\section{UCAPAN TERIMA KASIH}

Ucapan terima kasih kami ucapkan kepada DRPM Kemenristekdikti sebagai pemberi hibah dana kegiatan pengabdian masyarakat pada skema KKN PPM serta Lembaga Penelitian dan Pengabdian Masyarakat (LPPM) Universitas Ahmad Dahlan yang telah memberikan dukungan penuh dan Pemerintah Desa Wukirsari di Kabupaten Bantul, DIY atas berbagai fasilitas yang telah disediakan demi kelancaran kegiatan pengabdian masyarakat ini.

\section{DAFTAR PUSTAKA}

Badan Pusat Statistik. (2010). Hasil Sensus Penduduk 2010 (Vol. 6).

Cavazos-Rehg, P. A., Krauss, M. J., Spitznagel, E. L., Schootman, M., Cottler, L. B., Bierut, L. J., \& P. (2010). Associations Between Multiple Pregnancies and Health Risk Behaviors Among U. Journal of Adolescent Health, 47(6), 600-603.

CDC, T. C. for D. C. and P. (2002). Trends in Sexual Risk Behaviors Among High School Students -- United States, 1991--2001. Retrieved from https://www.cdc.gov/mmwr/preview/mmwrht $\mathrm{ml} / \mathrm{mm} 5138 \mathrm{a} 2 . \mathrm{htm}$ 
Kristianingrum, S., Atun, S., Handayani, S., Arianingrum, R., Purwaningsih, D., \& Kusumawardani, C. (2009). Pelatihan Diversifikasi Produk Wedang Uwuh Minuman Kesehatan Khas Imogiri yang Berkhasiat sebagai Antioksidan. Yogyakarta.

Kurniawan, A. B. (2011, November 24). Pernikahan Usia Dini di Bantul Melonjak - Kompas. Kompas. Retrieved from http://regional.kompas.com/read/2011/11/24/1 2591778/Pernikahan.Usia.Dini.di.Bantul.Melo njak

Munawaroh, S. (2014). Wedang Uwuh Sebagai Ikon Kuliner Khas Imogiri Bantul. Jantra, Jurnal Sejarah Dan Budaya, 9(1), 69-80.

Oljira, L., Berhane, Y., \& Worku, A. (2013). Assessment of comprehensive HIV/AIDS knowledge level among in-school adolescents in eastern Ethiopia. Journal of the International AIDS Society, 16, 11-15. https://doi.org/10.7448/IAS.16.1.17349

PKBI DIY. (2017, April 20). Perilaku Seksual Remaja. Perkumpulan Keluarga Berencana Indonesia DIY. Retrieved from http://pkbidiy.info/?p=4217

Purwitasari, N., Prajogo, B., \& Studiawan, H. (2016). IbM HOME INDUSTRY Pengrajin Jamu Godhokan dalam upaya meningkatkan daya saing menghadapi Masyarakat Ekonomi Asean. Surabaya. Retrieved from https://anzdoc.com/ibm-home-industrypengrajin-jamu-godhokan-dalam-upayamening.html

Rahman, A. A., Rahman, R. A., Ibrahim, M. I., Salleh, H., Ismail, S. B., Ali, S. H., ... Ahmad, A. (2011). Knowledge Of Sexual And Reproductive Health Among Adolescents Attending School In Kelantan, Malaysia. Southeast Asian J Trop Med Public Health, 42(3), 717-725.

Sumani, Wuryantoro, A., \& Kuswardani, Y. (2016). Penerapan "CPOTB" dalam Pengolahan Tanaman Obat Keluarga sebagai Ramuan Herbal. Jurnal Pemberdayaan Masyarakat, 1(1), 38-43. Retrieved from http://ejournal.unikama.ac.id/index.php/jpm/ar ticle/view/1430/1108

Wiyani, R., Yudiernawati, A., \& Maemunah, N. (2017). Pengaruh Pemberian Penyuluhan terhadap Pengetahuan pada Remaja Awal tentang Bahaya Narkoba di MAN 1 Kelas X Malang. Nursing News, 2(2), 772-782. 